\title{
Characterization by cDNA Cloning of the mRNA for Seminalplasmin, the Major Basic Protein of Bull Semen
}

\author{
SABINE WAGNER, JOHANNES FREUDENSTEIN, and KARL HEINZ SCHEIT
}

\begin{abstract}
A cDNA library derived from poly(A) ${ }^{+}$RNA of bull seminal vesicle tissue was screened with synthetic DNA probes specific for seminalplasmin (SAP), the major basic protein of bull semen. From a number of positive clones, pBSV12, containing a 577-bp insert, was identified and sequenced. The derived amino acid sequence comprises the known amino acid sequence of SAP with an amino terminal representing a putative signal sequence; at the carboxyl terminus the sequence contains an additional lysine residue. Present experimental data do not distinguish between two potential SAP precursor molecules, each starting with a methionine residue and differing by $\mathbf{1 0}$ amino acid residues in the leader peptide. Comparative Northern analysis reveals a SAP-specific mRNA of $\mathbf{7 0 0}$ bp, which lacks RNA from bovine testis as well as from seminal vesicle tissue of a bull calf; hence, expression of the SAP gene appears to be under androgen and/or developmental control. Southern analysis indicates that one gene appears to specify SAP. SAP-like DNA sequences were detected in ovine and porcine genomic DNA.
\end{abstract}

\section{INTRODUCTION}

$\mathrm{B}$ ULl SEMINAL PLASMa contains a highly basic protein of 47 amino acids of known sequence (Theil and Scheit, 1983; Lewis et al., 1985; Sitaram et al., 1986). This protein, originally discovered by Reddy and Bhargava (1979) and named seminalplasmin (SAP), possesses a number of interesting biological properties, including antimicrobial activity (Reddy and Bhargava, 1979; Scheit et al., 1986), calmodulin-antagonist function (Comte et al., 1986), inhibition of uptake of $\mathrm{Ca}^{2+}$ ions by epididymal bovine spermatozoa (Rufo et al., 1982), and inhibition of lymphocyte proliferation (Derwenkus et al., 1989).

Although SAP could be purified from the secretion of bull seminal vesicles (Scheit, 1986), an attempt to demonstrate the biosynthesis of SAP in this gland by immunohistochemical methods failed (Aumüller and Scheit, 1987). The reason for this failure might have been the use of an anti-SAP antiserum of low titer and specificity. Only recently, employing monospecific anti-SAP-IgGs (Krauhs et al., 1990), evidence for the biosynthesis of SAP in bovine seminal vesicles was obtained by immunohistochemistry and cell-free translation of poly(A) ${ }^{+}$RNA (Wempe et al., 1990). Here we report the sequence of a cDNA clone, de- rived from bull seminal vesicle tissue, that encodes the precursor of SAP.

\section{MATERIALS AND METHODS}

Seminal vesicles from slaughtered bulls and a male calf ( 2 weeks old) were collected immediately after killing. The secretion was squeezed out from the glands and the tissue was washed in ice-cold water, rapidly frozen, and stored in liquid nitrogen. Total RNA and poly(A) ${ }^{+}$RNA (Kemme et al., 1986; Kemme and Scheit, 1988) were prepared as described. cDNA synthesis followed the protocol of Gubler and Hoffman (1983) using a commercial cDNA synthesis kit (BRL). The procedure of Villa-Komaroff et al. (1978) was used for the construction of recombinant pBR322. Transformation of Escherichia coli RR1 was performed as published (Hanahan, 1983). The yield of transformation was $1.6 \times 10^{6}$ transformants $/ \mu \mathrm{g}$ poly(A) ${ }^{+}$RNA. Recombinants $\left(6 \times 10^{4}\right)$ were screened on replica nitrocellulose filters (Millipore HATF) with a ${ }^{32} \mathrm{P}$-labeled hybridization probe (sp. act., $2 \times 10^{8} \mathrm{cpm} / \mu \mathrm{g}$ DNA). Prehybridization and hybridization were performed according to Hanahan and Meselson (1983) at $60^{\circ} \mathrm{C}$. A total of 64 positive clones were identified. The Pst I insert of pBSV12 was purified

Max-Planck-Institut für biophysikalische Chemie, Göttingen, West Germany. 
on a $1 \%$ agarose gel and cut with Hae III, Alu I, Nco I, Hpa II, and Sau 3AI. The resulting individual mixtures were subcloned in M13mp19(RF). DNA sequencing was carried out by the dideoxy chain-termination method of Sanger et al. (1977). Oligonucleotides were synthesized using an Applied Biosystems DNA synthesizer model 318A.

For Northern transfer analysis, RNA was electrophoresed in a $1.5 \%$ agarose gel containing $2.2 \mathrm{M}$ glyoxal and transferred to GeneScreen membranes (NEN). Hybridization of RNA blots strictly followed the protocol of Khandjian (1986).

Bovine and human genomic DNA was prepared from blood anticoagulated with EDTA. Genomic DNAs from pig, sheep, hamster, mouse, and turkey were gifts from Dr. M. Zimmer. For Southern blot analysis, DNA was digested with restriction enzymes, electrophoresed in $0.7 \%$ agarose, and transferred to nitrocellulose membranes (BAS 85, Schleicher \& Schuell) essentially as described
(Southern, 1975). The blotting procedure was used with initial depurination by $\mathrm{HCl}$ treatment. Hybridization was performed at $60^{\circ} \mathrm{C}$ under stringent conditions following the protocol of Church and Gilbert (1984). DNA probes were ${ }^{32} \mathrm{P}$-labeled by random priming to a specific activity of $4 \times 10^{8} \mathrm{cpm} / \mu \mathrm{g}$ employing a commercial kit (Amersham).

DNA and protein sequence analysis as well as sequence comparisons were performed using the computer program of the University of Wisconsin Genetics Computer group (Devereux et al., 1984).

\section{RESULTS}

For detection of SAP-specific mRNA in poly(A) ${ }^{+}$RNA from bull seminal vesicle tissue, Northern hybridization was carried out employing synthetic DNA probes. The probes were designed on the basis of the known amino

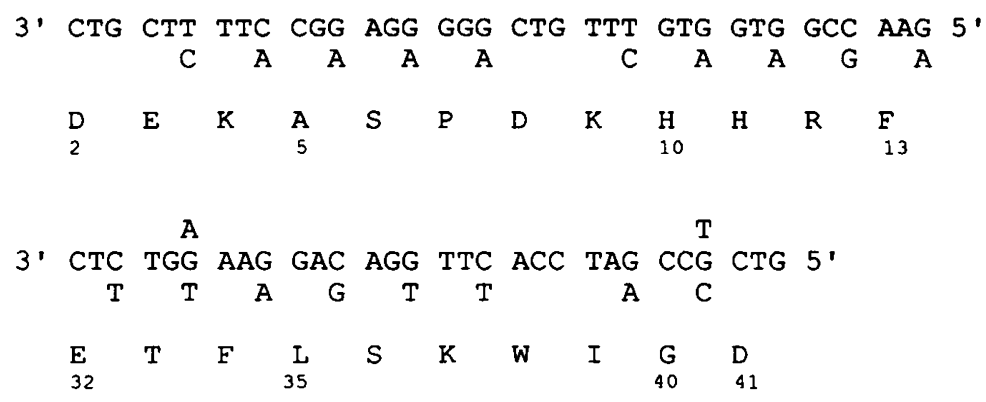

ON 1
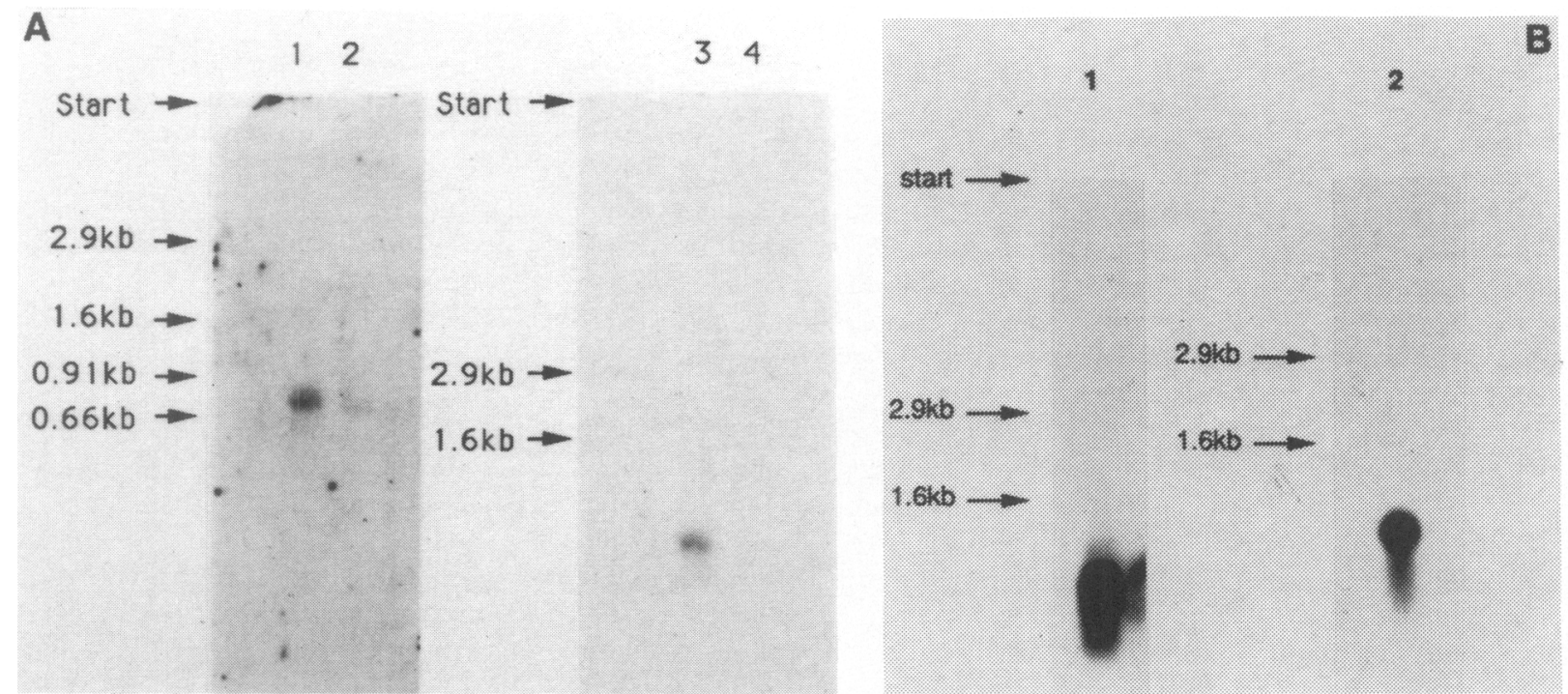

FIG. 2. Northern transfer analysis of bovine seminal vesicle and bovine testis poly(A) ${ }^{+}$RNA. A. Lane $1,3 \mu \mathrm{g}$ of poly(A) ${ }^{+}$RNA from seminal vesicle; lane $2,10 \mu \mathrm{g}$ of total seminal vesicle RNA; lane 3, $2 \mu \mathrm{g}$ of poly(A) ${ }^{+} \mathrm{RNA}$ from seminal vesicle; lane $4,3 \mu \mathrm{g}$ of poly(A) ${ }^{+}$RNA from bovine testis. Hybridization was performed with $\mathrm{ON}^{2}\left(4.6 \times 10^{8}\right.$ $\mathrm{cpm} / \mu \mathrm{g})$. B. Lane $1,3 \mu \mathrm{g}$ of poly(A)+RNA from seminal vesicle hybridized with the Pst I insert of clone pBSV12; lane 2 , poly(A) ${ }^{+}$RA from seminal vesicle hybridized with the Pst I insert of pBSV16. The specific activity of hybridization probes was $3 \times 10^{7} \mathrm{cpm} / \mu \mathrm{g}$. 

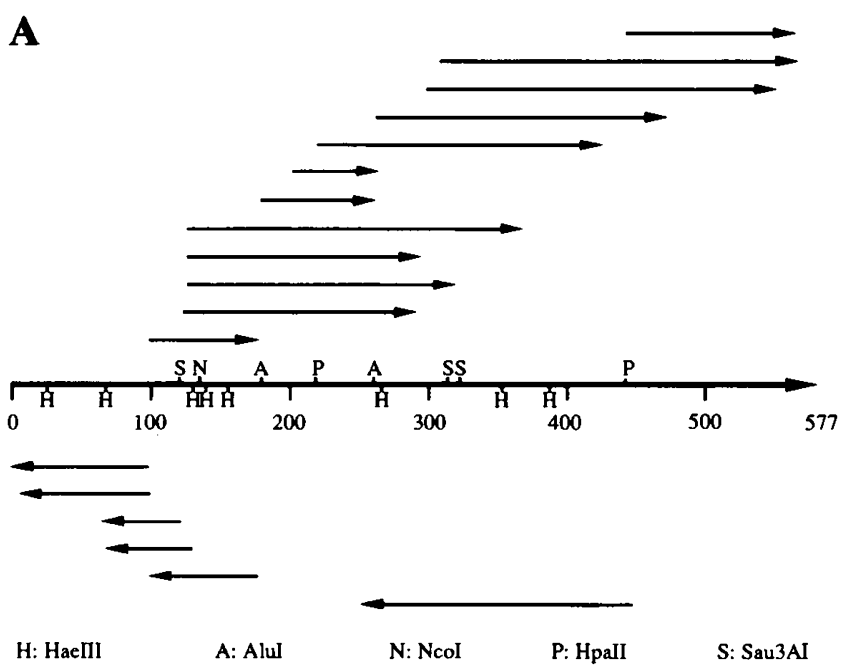

FIG. 3. cDNA sequence of pBSV12. A. Sequencing strategy and restriction map of pBSV12. Only restriction sites employed in sequencing are indicated. B. Nucleotide sequence of pBSV12 and deduced amino acid sequence of the SAP precursor. The amino acid sequence numbering starts with +1 for SAP. Putative signal sequences are underlined. The sequence regions corresponding to the hybridization probes $\mathrm{ON} 1$ and $\mathrm{ON} 2$ are also indicated.

\section{B}

61 CTCTGGCCTTCCATCTCCTGACCACTCTGCCTCTAGAGTGTCGCTATGATGGCGGGGCGC 120 $\begin{array}{lllllllll}S & V & A & M & M & A & G & R\end{array}$ $-32$

121 AGATCGTGGCCCGCCATGGCCACAGTGCTGCTGGCCCTGCTTGTCTGCCTGGGAGAGCTG 180

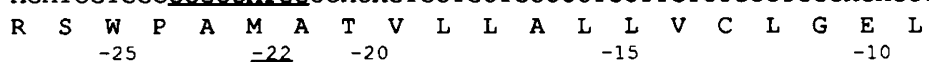

181 GTCGACTCCAAACCCCAGCCTTCAGATGAAAAAGCCTCACCGGATAAGCATCATCGTTTC 240

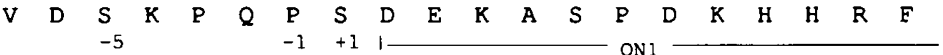

241 TCGCTGAGCCGCTATGCCAAGCTGGCCAATCGACTTGCGAATCCTAAACTCTTAGAAACT 300 $\begin{array}{lllllllllllllllllllll}S & L & S & R & Y & A & K & L & A & N & R & L & A & N & P & K & L & I & E & T\end{array}$

301 TTCCTCTCCAAATGGATCGgTGATCGCGGgAATCGCTCAGTCAAGTAGCGGCCAGAGGAG 360

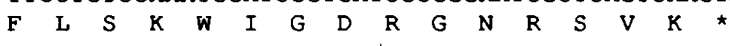

361 CCTAACTGTGGTGAAGACCGCTACGGCCTCCAGAGAGAAATATGCCAAGACACCGACCCC 420

421 ATTTCCATGTTTGCTCCTGACCCCGGAACCTGGATTCTTCTCCAGGCTGGCTATGTCTGA 480

481 GGAGTGTGTCCCTTCCTTGgGCTGGAgGGCTGTGAATGGTCCTTCCTTGTTCCCTAAATA 540

541 AAGTGCAAATTTCT-C 23

acid sequence (Theil and Scheit, 1983; Lewis et al., 1985; Sitaram et al., 1986). The amino acid sequences extending from residues 31-40 (ON1) and 2-13 (ON2) of the SAP sequence were chosen. A 30-nucleotide-long DNA (ON1) as well as a 36-nucleotide-long DNA (ON2), complementary to the corresponding SAP mRNA, were synthesized (Fig. 1). The selection of codons for the synthetic DNA probes was based on the codon usage derived from bovine mRNAs (Aota et al., 1988). A cDNA library derived from bull seminal vesicle poly(A) ${ }^{+}$DNA $\left(6 \times 10^{4}\right.$ recombinant clones) was screened by colony hybridization employing the radioactively labeled probe $\mathrm{ON} 2$. Hybridization at $60^{\circ} \mathrm{C}$, following the protocol of Hanahan and Meselson (1983), furnished 64 positive clones with cDNA inserts of lengths between 400 and $650 \mathrm{bp}$. Plasmid DNA from the purified positive clones was isolated and subjected to hybridization with the synthetic probes ON1 and ON2. Plasmid DNAs derived from clones carrying the complete coding region should hybridize to both ON1 and ON2, thus yielding higher signal intensities. Indeed, we observed three categories of hybridization intensities: low, medium, and high. Northern analysis of seminal vesicle poly(A) ${ }^{+}$RNA carried out with the synthetic probe ON2 using standard conditions at $42^{\circ} \mathrm{C}$ in $50 \%$ formamide, indicated the presence of a SAP-specific mRNA species of approximately 700 bp (Fig. 2); experiments with inserts of cDNA clones pBSV12 and pBSV16 led to similar results.

cDNA clone pBSV12, belonging to the strongly hybrid- 
izing group and carrying the longest Pst I insert of $\sim 600$ $\mathrm{bp}$, was sequenced. The sequencing strategy of clone pBSV12 is outlined in Fig. 3A. The nucleotide sequence obtained contains an open reading frame extending from nucleotide 97 to nucleotide 345 (Fig. 3B). The amino acid sequence derived from this open reading frame comprises the complete sequence of SAP. Surprisingly, the known amino acid sequence of SAP, which terminates with valine, contains an additional carboxy-terminal lysine residue in the derived amino acid sequence. Upstream of the amino-terminal serine residue of SAP, the derived amino acid sequence possesses 35 amino acid residues. Two methionine residues located at positions -22 and -32 might be translational starts of putative SAP precursor species. The corresponding methionine codons are part of the sequences GCCATGG and ATGATGG, respectively, which fulfill most of the criteria for a consensus sequence controlling translating efficiency of mammalian mRNAs (Kozak, 1984a,b, 1987; Lütke et al., 1987). Although the cDNA sequence of pBSV12 contains the polyadenylation signal AATAAA, starting at nucleotide 539 of the sequence, a poly(A) ${ }^{+}$tail is missing.

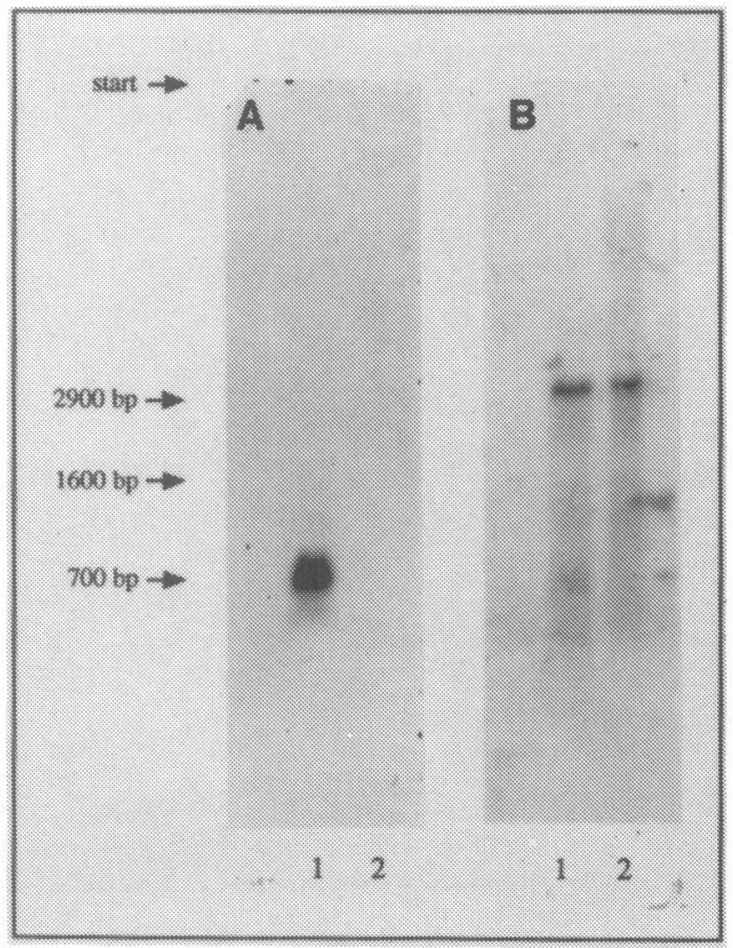

FIG. 4. Northern analysis of total RNA from mature bull and calf seminal vesicles. A. Lane $1,10 \mu \mathrm{g}$ of total RNA from seminal vesicle of a mature bull; lane 2, total RNA from seminal vesicle of a male calf (2 weeks old). The insert of cDNA clone pBSV12 (sp. act., $2.7 \times 10^{8}$ $\mathrm{cpm} / \mu \mathrm{g}$ ) was employed as hybridization probe. B. Lane $1,10 \mu \mathrm{g}$ of total RNA from seminal vesicle from a mature bull; lane $2,10 \mu \mathrm{g}$ of total RNA of seminal vesicle of male calf. The cDNA insert of the human elongation factor 2 clone pHGR81 was used for hybridization (sp. act., $3.4 \times$ $\left.10^{8} \mathrm{cpm} / \mu \mathrm{g}\right)$.
A comparative Northern analysis employing total RNA from seminal vesicle tissue of mature bull and of a male calf ( 2 weeks old) was performed. Only total RNA from mature bull gives the expected signal for the SAP-specific mRNA of 700 bp (Fig. 4). As a control, both RNA prepa -rations were hybridized with a DNA fragment comprising the coding region for the human elongation factor 2 (Rapp et al., 1989). Both RNA species reacted positively, indicating the presence of bovine elongation factor 2 mRNA $(\sim 3,500 \mathrm{bp})$ (Fig. 4). Hence, expression of the SAP gene may be androgen and/or developmentally controlled.

Male and female bovine genomic DNA was analyzed by Southern hybridization. After digestion with Eco RI, Hind III, Pst I, and Pvu II, enzymes known not to cut within the coding region of the cDNA insert of pBSV12, hybridization yielded single radiolabeled bands with each digest. Neither differences in the size of restriction fragments nor in the intensities of hybridization were seen between the fe-

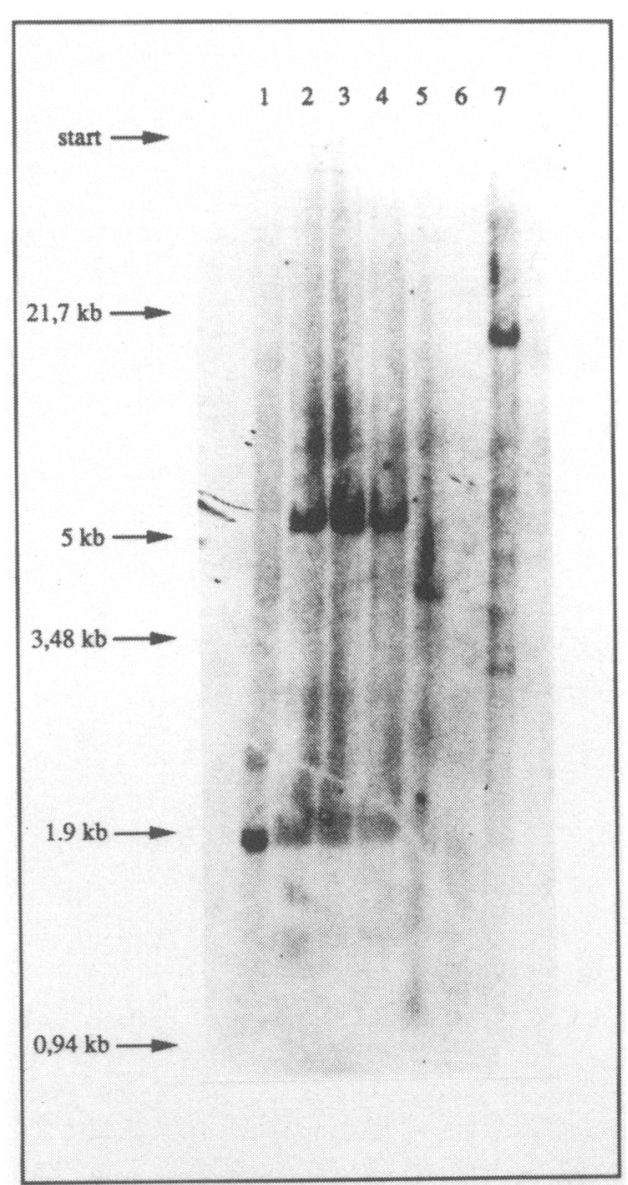

FIG. 5. Southern blot analysis of the gene for SAP. Bovine genomic DNA was digested with Taq I (lane 1, male individual A), Eco RI (lane 2), Eco RI (lane 3, male individual B), Eco RI (lane 4, female), Pst I (lane 5, female), Hind III (lane 6, female), and Pvu II (lane 7, female). A 230-bp fragment comprising the coding region was prepared by PCR and employed as hybridization probe (sp. act., $\left.5 \times 10^{8} \mathrm{cpm} / \mu \mathrm{g}\right)$. Hybridization was performed under stringent conditions. 
male and the male animals (Fig. 5). In the case of Taq I, which cuts twice within the coding region of the cDNA insert of pBSV12, two hybridization signals of similar size in the 1.9-kb range were detected by Southern analysis (Fig. 5). We tentatively infer from these experiments that there is one gene for SAP per haploid bovine genome.

Employing Southern hybridization, we attempted to detect SAP-related sequences in other species. Using a DNA fragment comprising the coding sequence of the cDNA insert of pBSV25 as a hybridization probe, no signals were found in genomic DNA of mouse, turkey, Chinese hamster, and monkey. However, besides a strong signal for bovine, significant hybridization signals were obtained for ovine and porcine genomic DNAs, respectively (Fig. 6).

\section{DISCUSSION}

The open reading frame of the cDNA insert extending from position 97 to 345 contains methionine codons at nucleotide positions 109 and 136 which are located within sequences that fulfill criteria of translational consensus

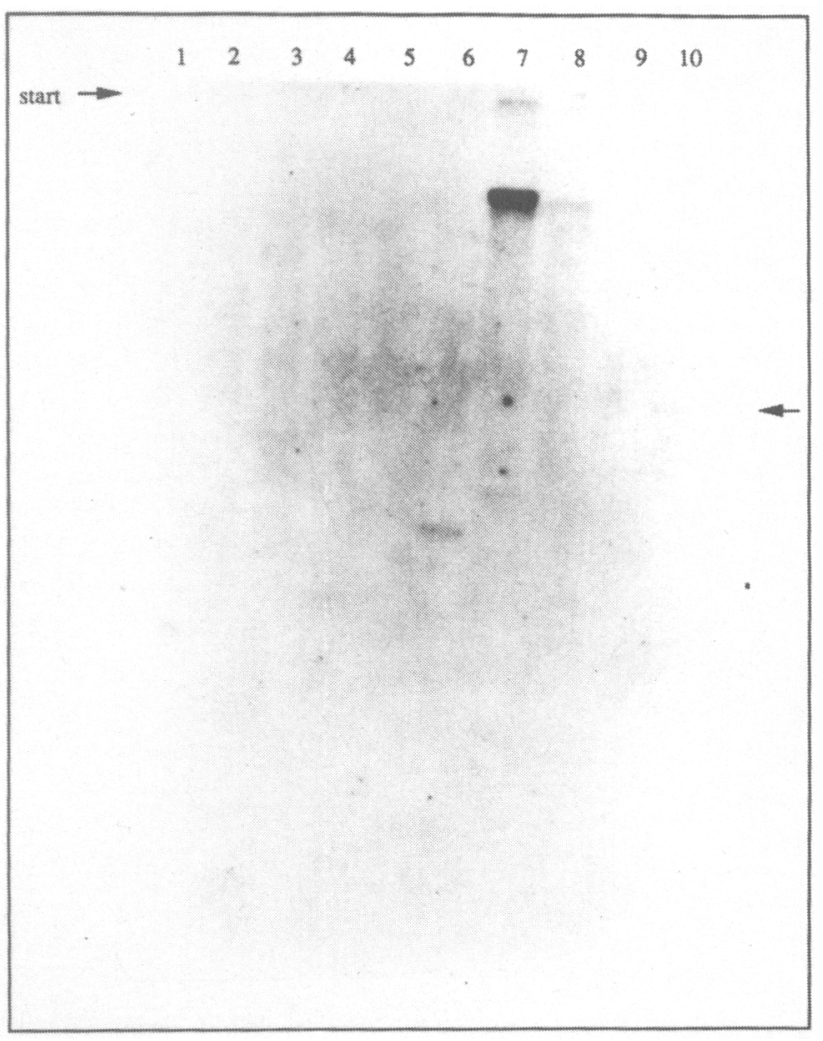

FIG. 6. Comparative Southern blot analysis. Genomic DNA (10 $\mu \mathrm{g}$ each) was digested with Eco RI: lane 1, $\lambda$ DNA; lane 2, turkey; lane 3, mouse; lane 4, chinese hamster; lane 5, syrian hamster; lane 6 , sheep; lane 7, bovine; lane 8 , porcine; lane 9, monkey; and lane 10, human. The hybridization probe employed was the same as in Fig. 5. Hybridization was performed under stringent conditions. The arrow indicates a weak signal in lane 10 . sequences (Kozak, 1984a,b, 1987; Lütke et al., 1987). According to Kozak (1984b) in most mammalian mRNAs the first A/G XX ATG of a long open reading frame is used as translational start. This would imply that the putative signal peptide for SAP comprises the amino-terminal extension of amino acid residues up to methionine -32 of the amino acid sequence; the corresponding $M_{\mathrm{r}}$ of the putative precursor would be 8,845 daltons. The second methionine codon within a consensus sequence at nucleotide position 136 leads to an amino-terminal extension of 22 amino acid residues. Hydropathy analysis of both amino-terminal extensions employing the algorithm of Kyte-Doolittle (data not shown) clearly favors the peptide fragment up to methionine -22 as a hydrophobic signal sequence, according to Austen (1979). However the latter SAP precursor possesses a $M_{\mathrm{r}}$ of 7,832 daltons, which does not agree with the size of the precursor $\left(M_{\mathrm{r}} \sim 10 \mathrm{kD}\right)$ as determined by cellfree translation (Wempe et al., 1990). However, SAP itself displayed an unusually high apparent $M_{\mathrm{r}}$ value of $\sim 8 \mathrm{kD}$ by $\mathrm{NaDodSO}_{4}$ polyacrylamide gel electrophoresis compared to the true $M_{\mathrm{r}}$ of 5,470 daltons.

The amino acid immediately proceeding the mature SAP peptide is a proline residue. This situation is rather uncommon for the linkage between signal peptides and the mature secreted proteins. However, a similar situation is encountered in the case of the precursor for elastin (Raju and Anwar, 1987).

The amino acid sequence derived from the cDNA is extended by an extra carboxy-terminal lysine residue. SAP, isolated from seminal vesicle secretion or bull seminal plasma, normally does not contain a carboxy-terminal lysine residue. Whether SAP prior to secretion undergoes both amino- as well as carboxy-terminal processing, thereby also losing the carboxy-terminal lysine extension, or whether the carboxy-terminal lysine is removed after secretion by specific carboxypeptidases present in seminal vesicles secretion has to await further investigation.

\section{REFERENCES}

AOTA, S.-i., GOJOBORI, T., ISIBASHI, F., MARUYAMA, T., and IKEMURA, T. (1988). Codon usage tabulated from the GenBank Genetic Sequence Data. Nucleic Acids Res. 16, 315-402.

AUMÜLLER, G., and SCHEIT, K.H. (1987). Immunohistochemistry of secretory proteins in the bull seminal vesicle. $\mathrm{J}$. Anat. 150, 43-48.

AUMÜLLER, G., VESPER, M., SEITZ, J., KEMME, M., and SCHEIT, K.H. (1988). Binding of a major secretory protein from bull seminal vesicles to bovine spermatoza. Cell Tissue Res. 252, 377-384.

AUSTEN, B.M. (1979). Predicted secondary structures of aminoterminal extension sequences of secreted proteins. FEBS Lett. 103, 308-313.

CHURCH, G., and GILBERT, W. (1984). A genomic sequencing. Proc. Natl. Acad. Sci. USA 81, 1991.

CLEMENS, M.J. (1985). In Transcription and Translation. A Practical Approach. E.B. Hames and S.J. Higgins, eds. (IRL Press, Oxford) pp. 252-255. 
COMTE, M., MALNOE, A., and COX, J.A. (1986). Affinity purification of seminalplasmin and characterization of its interaction with calmodulin. Biochem. J. 240, 567-573.

DERWENSKUS, K.H., SPRINZL, M., and SCHEIT, K.H. (1989). Inhibition of cell proliferation by basic proteins from bull seminal plasma. Biol. Chem. Hoppe-Seyler 370, 285-292.

DEVEREUX, J., HAEBERLI, P., and SMITHIES, O. (1984). A comprehensive set of sequence analysis programs for the Vax. Nucleic Acids Res. 12, 387-395.

GUBLER, U., and HOFFMAN, B.J. (1983). A simple and very efficient method for generating cDNA libraries. Gene 15, 263269.

HANAHAN, D. (1983). Studies on transformation of $E$. coli with plasmids. J. Mol. Biol. 166, 557-580.

HANAHAN, D., and MESELSON, M. (1983). Plasmid screening at high colony density. Methods Enzymol. 100, 333-343.

KEMME, M., MADIRAJU, M.V.V.S., KRAUHS, E., ZIMMER, M., and SCHEIT, K.H. (1986). The major protein of bull seminal plasma is a secretory product of seminal vesicle. Biochim. Biophys. Acta 884, 282-290.

KEMME, M., and SCHEIT, K.H. (1988). Cloning and sequence analysis of a cDNA from seminal vesicle tissue encoding the precursor of the major protein of bull semen. DNA 7, 595-599.

KHANDJIAN, E.W. (1986). UV-crosslinking of RNA to nylon membrane enhances hybridization signals. Mol. Biol. Rep. 11, 107-115.

KOZAK, M. (1984a). Point mutations close to the aug initiator codon affect the efficiency of translation of rat preproinsulin in vivo. Nature 308, 241-246.

KOZAK, M. (1984b). Compilation and analysis of sequences upstream from the translational start site in eukaryotic mRNAs. Nucleic Acids Res. 12, 857-872.

KRAUHS, E., PREUSS, K.D., and SCHEIT, K.H. (1990). Functional properties of peptides derived from seminalplasmin: Binding to monospecific anti-seminalplasmin IgGs and calmodulin. Biol. Chem. Hoppe-Seyler 371, 111-116.

LAEMMLI, U.K. (1970). Cleavage of structural proteins through the assembly of the head of bacteriophage T4. Nature 227, 680-685.

LEWIS, R.V., AUGUSTIN, J.S., KRUGGEL, W., and LARDY, H.A. (1985). The structure of caltrin, the calcium transport inhibitor of bovine seminal plasma. Proc. Natl. Acad. Sci. USA 82, 6490-6491.

LÜTKE, H.A., CHOW, K.C., MICKEL, F.S., MOSS, K.A., KERN, H.F., and SCHEELE, G.A. (1987). Selection of AUG initiation codons differs in plants and animals. EMBO J. 6, 43-48.

PALMIERI, M., CARSANA, A., FURIA, A., and LIBONATI,
M. (1985). Sequence analysis of a cloned cDNA coding for bovine seminal ribonuclease. Eur. J. Biochem. 152, 275-277.

RAJU, K., and ANWAR, R.A. (1987). Primary structures of bovine elastin $a, b, c$ deduced from the sequences of cDNA clones. J. Biol. Chem. 262, 5755-5762.

REDDY, E.S.P., and BHARGAVA, P.M. (1979). Seminalplasmin, an antimicrobial protein from bovine seminal plasma which acts in $E$. coli by specific inhibition of rRNA synthesis. Nature 279, 725-728.

RUFO, G.A., SINGH, J.P., BABCOCK, D.F., and LARDY, H.A. (1982). Purification and characterization of a calcium transport inhibitor protein from bovine seminal plasma. J. Biol. Chem. 257, 4627-4632.

SANGER, F., NICKLEIN, S., and COULSON, A.R. (1977). DNA sequencing with chain-terminating inhibitors. Proc. Natl. Acad. Sci. USA 74, 5463-5467.

SITARAM, N., KUMARI, V.K., and BHARGAVA, P.M. (1986). Seminal plasmin and caltrin are the same protein. FEBS Lett. 201, 233-236.

SCHEIT, K.H., ZIMMER, M., RAO, N.S., PRASAD, K.S.N., and BHARGAVA, P.M. (1986). Antibacterial activity of seminalplasmin, a basic protein from bovine seminal plasma. Microbios 45, 105-112.

SCHEIT, K.H. (1986). The major proteins of bull seminal plasma. Biol. Chem. Hoppe-Seyler 367, 1173-1180.

SOUTHERN, E. (1975). Detection of specific sequences among DNA fragments separated by gelelectrophoresis. J. Mol. Biol. 98, 503-517.

THEIL, R., and SCHEIT, K.H. (1983). Amino acid sequence of seminalplasmin, an antimicrobial protein from bull semen. EMBO J. 2, 1159-1163.

VILLA-KOMAROFF, L., EFSTRADIADIS, A., BROOME, S., LOMEDICO, P., TIZARD, R., NAKER, S.P., CHICK, W.L., and GILBERT, W. (1978). A bacterial clone synthesizing proinsulin. Proc. Natl. Acad. Sci. USA 75, 3727-3731.

WEMPE, F., WAGNER, S., v.D. KAMMER, H., KRAUHS, E., and SCHEIT, K.H. (1990). Seminalplasmin, the major basic protein of bull seminal plasma is a secretory protein of seminal vesicles. Biochim. Biophys. Acta (in press).

\section{Address reprint requests to: Dr. Karl Heinz Scheit Max-Planck-Institut für biophysikalische Chemie Göttingen, West Germany}

Received for publication March 14, 1990, and in revised form May 11, 1990. 